\title{
A gênese de uma cultura ceramista
}

\section{(The genesis of a potter culture)}

\author{
K.J. da Silva \\ Departamento de Arquitetura Urbanismo e Artes Aplicadas, Universidade Federal de S. João Del Rei \\ Av. Visconde do Rio Preto, s/n, km 2, Prédio REUNI, Sala 3.01RE, Colônia do Bengo, \\ S. João del-Rei, $M G$, 36301-360 \\ kjs@ufsj.edu.br
}

\begin{abstract}
Resumo
A instalação do Ateliê do Antigo Matadouro na cidade de Cunha, SP, no ano de 1975, representa a gênese de uma nova cultura ceramista. O pioneirismo deste grupo estabeleceu bases para a criação de um dos mais importantes polos ceramistas brasileiros da atualidade e que continua a inspirar a criação de novos ateliês que têm nas queimas a lenha de alta temperatura, parte fundamental de sua poética de criação.

Palavras-chave: cerâmica artística de alta temperatura, Cunha, forno Noborigama, Ateliê do Antigo Matadouro.
\end{abstract}

\begin{abstract}
The installation of the Ateliê do Antigo Matadouro (Old Slaughterhouse Studio) in the city of Cunha, S.P., Brazil, in 1975, is the genesis of a new potter culture. The pioneering action of this group established the bases for creation of one of the most important Brazilian pottery clusters in nowadays, and continues to inspire the creation of new studios that have the firing of firewood at high temperature, fundamental part of his poetic creation.

Keywords: high temperature potteries, Cunha, Noborigama kiln, Ateliê do Antigo Matadouro.
\end{abstract}

\section{INTRODUÇÃO}

Situado a extremo leste do Estado de S. Paulo, na região conhecida como Vale do Paraíba (Fig. 1), o município de Cunha tem sua origem atrelada à rota de escoamento do ouro extraído das Minas Gerais para o porto de Paraty, RJ, com destino a Portugal, em meados do século XVIII. Nesta época, a cidade de Cunha consolidou-se como parada obrigatória para tropeiros que trilhavam o caminho, a ponto de atrelar amplamente sua economia ao abastecimento destes viajantes. É neste contexto que emerge uma das primeiras manifestações da cultura ceramista no Município: a Cerâmica das Paneleiras.

Com o aumento substancial nos volumes da mineração do ouro, o caminho Minas Gerais-Paraty, que normalmente durava por volta de dois meses para ser percorrido, passa a não atender com tanta propriedade às necessidades de escoamento da produção. Uma nova rota é então estudada e quando entra em plena operação (segunda metade do século XVIII) o Caminho Novo permite percorrer de Ouro Preto, $\mathrm{MG}$, à cidade do Rio de Janeiro em cerca de 15 dias (a cavalo), tornando obsoleto o caminho Minas-Paraty. Pouco a pouco "Cunha, antes uma etapa importante numa das maiores vias de comunicação do Brasil meridional, é deixada à margem e finalmente esquecida" [1]. Cunha só volta a figurar de forma relevante no cenário econômico regional a partir da década de 1990, com a consolidação de uma série de ateliês de cerâmica, nascidos pela influência direta daquele

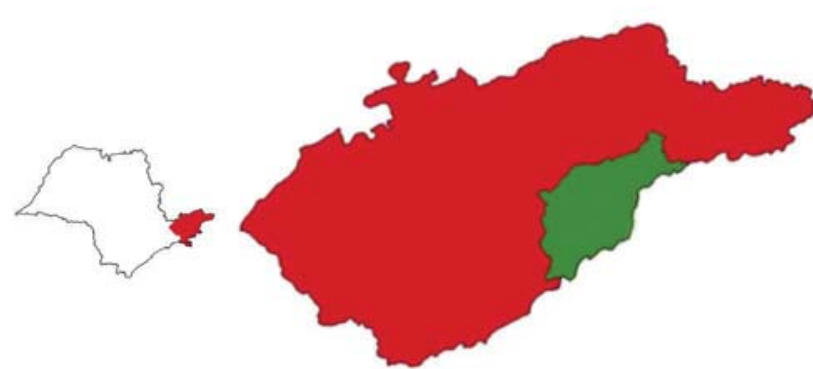

Vale do Paraíba Cunha

Figura 1: Mapa do Estado de S. Paulo, com destaque para a região do Vale do Paraíba e Cunha.

[Figure 1: Map of the State of S. Paulo, with emphasis on the region of the Paraiba Valley and Cunha.]

que foi o precursor da cultura ceramista de Alta Temperatura na cidade, o grupo fundador do Ateliê do Antigo Matadouro.

\section{UMA HISTÓRIA DE PIONEIRISMO}

A partir da chegada deste grupo que se insere na cultura ceramista local, até então referenciada pela produção de tijolos em olarias e confecção de panelas de barro, uma série de outras referências sobre a concepção e criação do objeto cerâmico, tais como: a assinatura como forma de evocar a autoria dos trabalhos; a introdução do esmalte como elemento estético e estrutural; o torno elétrico como ferramenta de modelagem; o ateliê como espaço de criação; o 
forno enquanto estrutura construída com tijolos refratários; e a queima em alta temperatura. Amparados por algumas peças de mostruário, Mieko Ukeseki, Toshiyuki Ukeseki, Rubi Imanishi (japoneses), Alberto Cidraes (português), Vicente Cordeiro - Vicco e seu irmão Antônio Cordeiro - Toninho (os únicos brasileiros do grupo) chegaram a Cunha no mês de setembro do ano de 1975. Dizendo estar procurando um local para instalar um ateliê coletivo de cerâmica, conseguiram convencer o então prefeito José Elias Abdalla (Zelão, Fig. 2) a ceder, em regime de comodato, as instalações do antigo matadouro municipal, para instalação do tal ateliê. Daí o nome: Ateliê do Antigo Matadouro. Muito provavelmente, Zelão percebeu na proposta do grupo uma possibilidade, mesmo que remota, de alavancar o turismo na cidade que, apesar de ser considerada já no ano de 1948 uma das poucas instâncias climáticas do Estado de S. Paulo, até então não havia se projetado como local de frequentação turística.

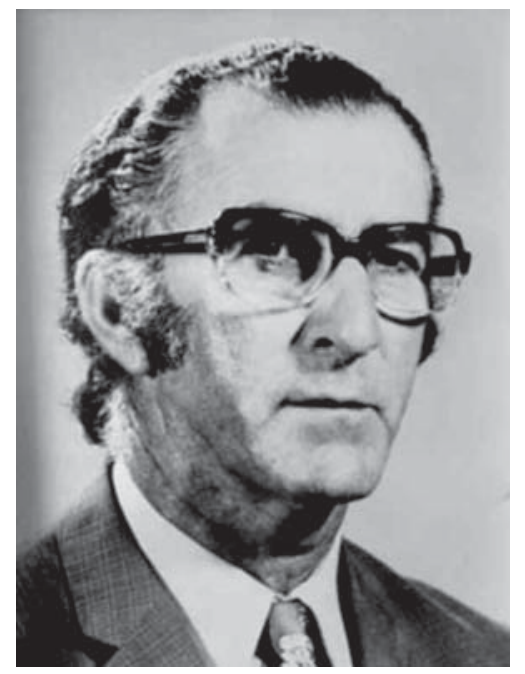

Figura 2: Foto de José Elias Abdalla (Zelão), 1974 [2].

[Figure 2: Photograph of Jose Elias Abdalla (Zelão), 1974 [2].]

Independente das motivações que o prefeito da cidade possa ter tido, o fato é que para aquele grupo de amigos a escolha daquela região para a instalação do ateliê nada teve de acaso. O grupo queria se instalar em alguma cidade do eixo Rio-S. Paulo, por serem os dois maiores mercados consumidores brasileiros e Cunha fica praticamente no meio deste caminho (a $227 \mathrm{~km}$ de S. Paulo e $280 \mathrm{~km}$ do Rio de Janeiro). Apesar de já terem percorrido várias cidades da região e até mesmo encontrado no município de Lagoinha uma propriedade à venda, cujas características atendiam suas necessidades, diante da oferta de cessão gratuita do espaço feita por Zelão, optaram por se instalar em Cunha. Também o relevo montanhoso da região foi fator determinante para a instalação dos ceramistas, isso por causa do tipo de forno escolhido por eles, como ferramenta de trabalho: o forno Noborigama (tipo de forno cerâmico, inventado na China a mais de 3000 anos, feito de tijolos refratários dispostos em forma de arcos e em degraus ascendentes, alimentado à lenha, cuja temperatura interna pode atingir patamares superiores a $1400{ }^{\circ} \mathrm{C}$; o nome é resultante da união das palavras japonesas noboru (rampa) + kama (forno); a tradução literal da palavra noborigama é forno que sobe a rampa). Uma das características deste tipo de equipamento é sua vocação rural: pelas dimensões avantajadas e por usar lenha como combustível, seu uso no meio urbano torna-se inviável; também sua arquitetura, em degraus ascendentes, otimiza o aproveitamento do calor, ou seja, ele precisa de um terreno íngreme para ser construído.

O Ateliê do Antigo Matadouro consubstancia uma ideia gestada muito distante dos limites geográficos de Cunha e mesmo do Brasil. No ano de 1972, o arquiteto Alberto Cidraes, então com 27 anos de idade, acompanhado de sua esposa Maria Estrela, estava a estudar habitação tradicional no Japão. À medida que se davam seus estudos no campo da arquitetura, outras descobertas começavam a cativar os olhares do jovem casal, entre as quais, a maior e mais transformadora foi sem dúvida a Cerâmica Japonesa. A história, as formas, as cores, a relação com a natureza e a meticulosidade do acabamento de cada peça lhes encantam a ponto de produzir e queimar algumas peças, em fornos de amigos ceramistas. Neste período conhecem o casal Ukeseki: Toshiyuki, um jovem ceramista, tendo como grande ideal poder um dia ter em seu ateliê um forno Noborigama, e Mieko, enfermeira por formação, ceramista por opção. Influenciados pelo pensamento de ceramistas como Shoji Hamada, Kanjiro Kawai e Kenkichi Tomimoto, que no início do século XX criaram no Japão o Movimento chamado Mingei, gestaram então a ideia de construção coletiva de um ateliê. No entanto, voltar para Portugal implicaria a Alberto a obrigação de alistamento nas forças armadas, em guerra com colônias africanas (Angola, Guiné Bissau e Moçambique); por outro lado, devido aos altos custos de produção, tentar implementar o ateliê no Japão seria algo igualmente inviável. O plano de virem para o Brasil surge a partir de conversas de Alberto com alguns amigos brasileiros, conhecidos desde quando ainda estudava arquitetura em Portugal.

No ano de 1973 Alberto Cidraes e Maria Estrela chegam ao Brasil, mais especificamente à cidade de S. Paulo, onde trabalharam por alguns meses respectivamente como arquiteto e intérprete de língua inglesa. Conhecem Gilberto Jardineiro e os irmãos Vicente (Vicco) e Antônio Cordeiro (Toninho); um ano depois, Alberto Cidraes, Maria Estrela, Antônio Cordeiro e Gilberto Jardineiro mudam-se para o estado da Bahia, ilha de Itaparica, na comunidade de Cachaprego. Em busca de um convívio mais próximo com a natureza, formaram o Grupo Take (Bambu, Fig. 3), experiência esta que dura dois anos e que seria segundo depoimento de Alberto Cidraes "o germe precursor do grupo que se instalaria em Cunha no ano de 1975" [3]. Um dos traços que contribuiu para a agregação do grupo era a maneira comum de ver a cerâmica e a vida. "Nosso projeto passava pelo naturalismo e pelo experimentalismo", explica Alberto Cidraes. "Queríamos queimar a lenha em forno Noborigama e usar para a produção das peças, o que a natureza oferecia: barro, os materiais de esmalte, as cinzas da lenha empregada na queima das peças" [4]. Apesar desta "maneira comum de 
ver a cerâmica e a vida", o grupo que ficou conhecido como Grupo do Antigo Matadouro durou pouco mais de sete meses com sua formação original. O convívio diário fez aflorar nuances de relacionamento que acabaram por afetar o convívio e a dinâmica da coletividade, fazendo com que seus membros, todos eles, em algum momento fossem buscar novas experiências fora dali. Alguns acabaram voltando, como no caso de Alberto e Mieko, outros encontraram seus rumos em outros lugares e jamais voltaram: Toshiyuki de volta ao Japão continua exercendo o ofício de ceramista; Rubi Imanishi de volta a S. Paulo retomou o desenho como prática expressiva; os irmãos Cordeiro seguiram para Teresópolis, RJ, e construíram seus ateliês, vindo a falecer Toninho em 1991 e Vicco em 1998.

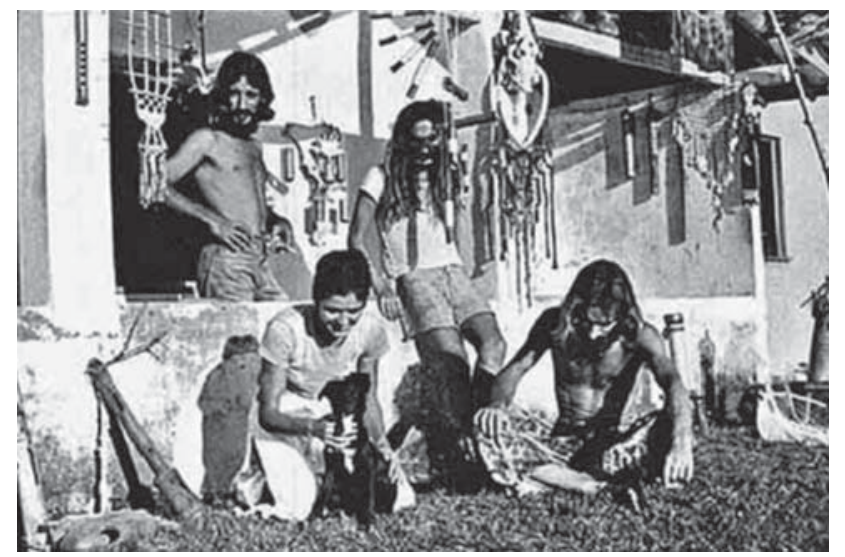

Figura 3: Foto do Grupo Take: Alberto Cidraes, Maria Estrela, Antônio Cordeiro e Gilberto Jardineiro, 1974 (fonte: acervo de Alberto Cidraes).

[Figure 3: Photograph of Take Group: Alberto Cidraes, Maria Estrela, Antônio Cordeiro, and Gilberto Jardineiro, 1974 (source: collection of Alberto Cidraes).]

Apesar do pouco tempo de atuação coletiva, a experiência vivida por este grupo estabeleceu as bases para o desenvolvimento de uma nova cultura ceramista local, estandartizada na figura do forno Noborigama. "O forno Noborigama, explica Alberto Cidraes, é a forma mais sofisticada do forno arcaico, a lenha, de Alta Temperatura do Extremo Oriente. Evoluiu de uma linhagem de fornos que vem da China, passou pela Coréia e adquiriu no Japão seu maior refinamento, associado à cultura Zen. A sofisticação técnica vem da funcionalidade ligada à otimização na economia de combustível e organização na carga, descarga e operação" [4]. Pode-se dizer que foi por este forno que aquele projeto sonhado, nascido no Japão no ano de 1972, só se tornou realidade porque estava baseado na operação deste tipo de forno. Aos integrantes daquele grupo não interessava apenas fazer cerâmica de alta temperatura, mas sim cerâmica queimada em forno Noborigama (Fig. 4), por todo referencial histórico que ele traz consigo, a ponto de ser considerado patrimônio nacional japonês, pela mística que envolve sua manutenção e pela relação imposta por ele, de proximidade com a natureza. Em Cunha, o trabalho com este forno imprimiu outros olhares sobre a relação até então existente entre o objeto cerâmico

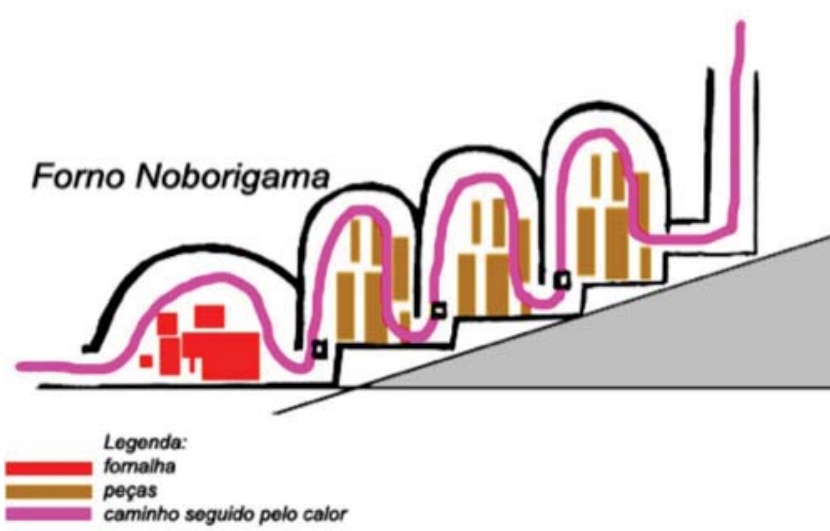

Figura 4: Desenho esquemático do forno Noborigama. [Figure 4: Schematic drawing of Noborigama kiln.]

e sua relevância no cenário artístico e econômico da cidade. Com sua chegada, o objeto cerâmico passa a refletir de forma mais substancial seu valor artístico e com o passar do tempo passou a figurar também como foco de atração turística, contribuindo com o fortalecimento da economia local. $\mathrm{O}$ fluxo cada vez maior de pessoas interessadas em conhecer a cerâmica ali produzida acabou por viabilizar a instalação de toda uma infraestrutura hoteleira e gastronômica na cidade. E por que ele consegue isso? Justamente pela forma que os ceramistas encontraram de explorar os diversos apelos a ele relacionados: raro, grande, temperamental, milenar, oriental, rural, temperatura de queima e mística.

O forno Noborigama é por natureza um gigante, seja em suas dimensões (em Cunha há fornos com mais de $12 \mathrm{~m}$ de comprimento), em seu espaço interno (capaz de acomodar centenas de peças), na capacidade de atingir altas temperaturas (há ateliês que queimam peças a $1400{ }^{\circ} \mathrm{C}$ ), no tempo de queima (entre 26 a $40 \mathrm{~h}$ ininterruptas), na quantidade de lenha necessária para aquecê-lo (cerca de $5 \mathrm{~m}^{3}$ para queima em Alta Temperatura) e no número de tijolos necessários para sua confecção (cerca de 1000 para cada câmara, dependendo das dimensões a serem aplicadas). Como se não bastasse toda essa magnitude, o domínio de seus "humores" relaciona-se diretamente com uma mística votiva, expressa de diferentes formas nos ateliês. Em alguns deles encontrase sobre a fornalha uma peça feita pelo ceramista, figurando como um totem a proteger o forno de eventuais intempéries, ou qualquer tipo de situação que por ventura possa vir a causar algum desequilíbrio no processo de queima. Um recipiente com saquê, para alegrar os "deuses" que regem os elementos da natureza (água, terra, ar, fogo), uma pequena vasilha com arroz, aludindo votos de fartura para aquela casa, e uma ramagem verde, evocando a beleza singela da natureza, também figuram como elementos pertencentes a esta vivência que envolve, com inúmeras variações formais e conceituais, a produção ceramista desde seus primórdios. Esta relação votiva transparece também no depoimento dos ceramistas, como nas palavras do ceramista Alberto Cidraes: "Eu não só fiz a escolha da queima em alta temperatura, como fiz a escolha da queima a lenha, mais especificamente a queima em forno Noborigama, porque o forno Noboriga- 
ma e a queima a lenha foram dois aspectos da cerâmica que fizeram parte do meu encantamento pela cerâmica no Japão [...] me encantei pelo barro como um veículo de autoexpressão que permite qualquer tipo de forma, e qualquer tipo de modelagem, e também a parte de transformação que é uma coisa meio litúrgica, meio mágica, a transformação do barro em pedra, através da queima em alta temperatura, $[. ..] \mathrm{e}$ como eu já era arquiteto, o forno Noborigama tem um aspecto muito interessante de arquitetura e de arquitetura dinâmica no sentido que é uma ferramenta que proporciona essa transformação do barro em pedra. Então a lenha e o forno Noborigama foram parte dessa minha entrada na cerâmica; eu não faria cerâmica se não fosse em forno Noborigama e não tenho o menor interesse em fazer cerâmica num forno a gás ou num forno elétrico" [3].



Figura 5: Foto de Kimiko Suenaga junto ao forno Noborigama instalado em seu ateliê.

[Figure 5: Photograph of Kimiko Suenaga in a Noborigama kiln installed in her studio.]

Entre os anos de 1975 e 1988, Cunha contava com quatro ateliês de cerâmica, remanescentes diretos do Ateliê do Antigo Matadouro, e praticamente toda a produção era comercializada com galerias, lojas de decoração e shoppings principalmente das cidades de S. Paulo e Rio de Janeiro. Apenas na década de 1990 é que se estabelece um canal consistente de comunicação que efetivamente aproximou o consumidor final da cerâmica ali produzida. Por meio das aberturas de fornada (kamabiraki), promovidas inicialmente pelo ateliê de Gilberto Jardineiro e sua esposa Kimiko Suenaga (instalados em Cunha desde o ano de 1984), a cerâmica de Cunha passa cada vez mais a ganhar visibilidade e consequentemente a atrair novos ceramistas. Em dia de kamabiraki, Gilberto Jardineiro assume o papel de "mestre de cerimônia". Em horários predefinidos (10:00 h, 12:00 h, 14:00 h e 16:00 h), abre-se uma das câmaras do forno, cada qual acompanhada por uma explicação fervorosa sobre aspectos geológicos, históricos, estruturais, do objeto cerâmico e do forno Noborigama. Durante aproximadamente 1 h, ele entretém os visitantes, alternando entonações de voz, piadas, seriedade, explicações teóricas, práticas (pintura de peças, estados da argila, composição de esmaltes, tipos de minerais usados, diferença estética entre queimas de Alta e Baixa Temperatura, etc.). Munido deste grande leque de possibilidades, o Ateliê Suenaga e Jardineiro consegue apresentar a cerâmica por um viés onde a história, a pesquisa de materiais e a ação profissional, coletiva e coordenada de toda uma equipe de trabalho, atrelam-se em prol de um objetivo comum; tudo isso sem que seja necessário abrir mão de sua dimensão "mágica", inerente a este tipo de ofício. Criase um belo contraponto à visão romântica de cerâmica como sendo apenas um trabalho harmonioso e prazeroso com os quatro elementos da natureza: fogo, terra, água e ar. Ao final da apresentação, com a câmara já aberta, não raramente as cerâmicas são retiradas sob flashes e aplausos; a empolgação do público, encantado com a riqueza da quantidade de informações recebidas, leva algumas pessoas até mesmo a "disputar" por determinadas peças. "Receber a visita no próprio ateliê e vender a peça no próprio ateliê têm duas coisas muito positivas, primeiro para o ceramista que se desvencilha do problema de vender a peça, porque fazer a peça é uma coisa muito prazerosa [...]. Conhecer as pessoas que vão usar, que vão levar a sua cerâmica, pode parecer uma coisa desnecessária do ponto de vista artístico, mas do ponto de vista da cerâmica é fantástico você conhecer as pessoas que olham para sua cerâmica e falam: nossa que legal, eu vou levar isso. Então a coisa do vender a cerâmica é uma questão que pouco se discute, porque é uma coisa comercial e tal, mas é ela que define como você vai ser como ceramista [...] no nosso caso nós encontramos uma fórmula bem legal de vender a cerâmica, no próprio ateliê, conversa, explica, a pessoa não leva só o objeto, essa é uma coisa legal, ela leva o objeto e a sua história, isso é importante para a cerâmica" [5]. Conseguir desvincular a venda de seus trabalhos, da necessidade de oferecê-los a galerias, lojas de decoração e feiras de outros centros urbanos, institui localmente uma nova mentalidade de comercialização do objeto cerâmico que passa a ser apresentado como um bem cultural, com alto valor agregado. Com isso a cerâmica passa a atrair cada vez

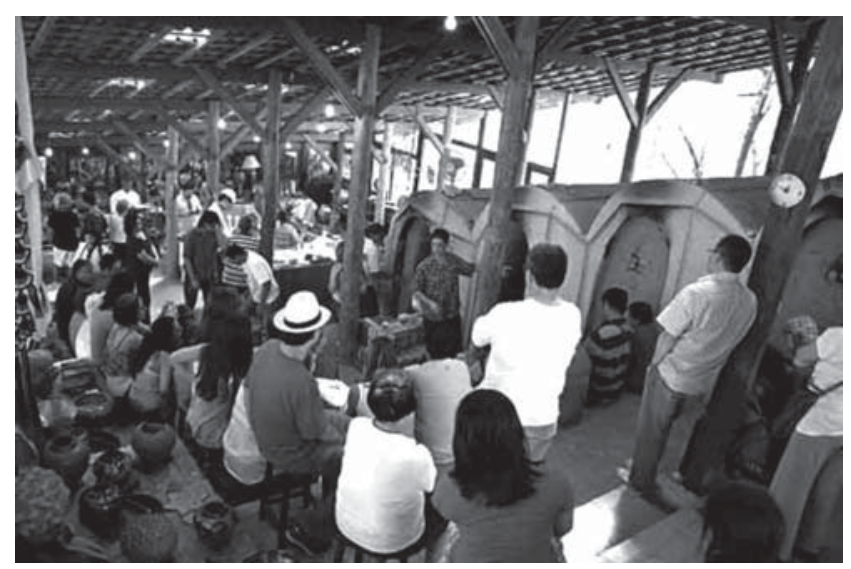

Figura 6: Foto de abertura de forno no Ateliê Suenaga e Jardineiro (fonte: www.cunhatur.com.br).

[Figure 6: Photograph of kiln opening in the Suenaga and Jardineiro Studio (source: www.cunhatur.com.br).] 
mais pessoas e impulsionar uma série de investimentos na economia local, voltados principalmente para o acolhimento turístico, como também estimulam a chegada de novos ceramistas, colaborando para que a cidade seja cada vez mais reconhecida como importante polo ceramista nacional. Mais recentemente, a partir do ano 2000, novos artistas/ateliês também se instalaram ali, trazendo outros olhares, outras referências, outros tipos de fornos, contribuindo ainda mais para que Cunha pudesse chegar aos dias atuais, figurando como um grande polo produtor de cerâmica artística, principalmente de alta temperatura.

\section{CONSIDERAÇÕES FINAIS}

Em Cunha, ao longo destes últimos 40 anos, paralelamente à decadência das olarias e o praticamente desaparecimento das Paneleiras, a cerâmica produzida em ateliês, graças à experiência do grupo do Antigo Matadouro, imprimiu outros olhares sobre a relação até então existente entre o objeto cerâmico e sua relevância no cenário artístico e econômico da cidade. Aquilo que anteriormente cumpria funções muito específicas dentro da dinâmica social local, no caso das olarias o uso da cerâmica na arquitetura e as Paneleiras com a função de suprir, em dado momento histórico, principalmente com seus potes e panelas, necessidades utilitárias das famílias locais, passa a figurar também como foco de atração turística e aos poucos se enquadrar com objeto de valor artístico. Curiosamente, do Antigo Matadouro de Cunha, ao revés de sua finalidade primeira, produziu-se vida. Desta semente nasceram outros ceramistas, Augusto de Campos Leí Galvão e Luiz Toledo, a princípio atuando como aprendizes, mas que acabaram rapidamente emancipando-se a ponto de formar seus próprios ateliês. Ali instalados até hoje, são também mantenedores da queima em alta temperatura, do forno Noborigama, do olhar ritualístico para a produção e queima das peças. Com o passar dos anos, a produção de tais ceramistas, aliada às memórias da cerâmica já produzida na cidade, mais que consolida o "fazer cerâmica" como uma das vocações do Município, o que deu início a uma nova cultura ceramista que reverbera por grande parte do território nacional.

\section{REFERÊNCIAS}

[1] E. Willens, Cunha, Tradição e Transição em uma Cultura Rural do Brasil, Secretaria da Agricultura, S. Paulo, SP (1947).

[2] J.J.O. Veloso, A História de Cunha - Freguesia do Facão - A Rota de Exploração das Minas e Abastecimento de Tropas, Cunha-SP: Centro de Cultura e Tradição de Cunha, JAC Gráfica e Editora (2010).

[3] C.A. Cidraes, Mestres da Cerâmica, DVD, Ed. K. J. da Silva, Santa Isabel (2010).

[4] M. Ukeseki, 30 anos de Cerâmica em Cunha, JAC Gráfica e Editora, Cunha, SP (2005).

[5] G. Jardineiro, S. Kimiko, Mestres da Cerâmica. Ateliê Suenaga e Jardineiro, DVD, Ed. K.J. da Silva, Santa Isabel (2011).

(Rec. 28/07/2015, Rev. 13/10/2015, Ac. 25/10/2015) 